\title{
Formal features and intonation in Persian speakers' English interlanguage wh-questions
}

Laya Heidari Darani

English Department, Azad University, Iran

https://doi.org/10.36505/ExLing-2006/01/0021/000021

\begin{abstract}
The Unitarianist Interface Hypothesis proposed by Lotfi (ms.) concerns only one interface level -the Semantico-Phonetic Form- at which both performance systems can have access to various types of features of a lexical item. This paper hypothe-sizes the existence of an iconic relationship between formal and phonological fea-tures, and the influence of formal features on intonation in Persian speakers' English interlanguage wh-questions. The present study is based on computing t-test proce-dure on the data obtained from twenty-four Iranian L2 learners of English age-ranged between twelve and sixteen. The comparison of the data collected from the syntax and intonation tests before and after the instruction confirms the above hy-potheses.
\end{abstract}

\section{Introduction}

This paper is a report on an SLA research project in Phonology and Minimalist Syntax with specific reference to formal features and phonological features.

Lotfi (ms.), contrary to Chomsky (1995), proposes a hypothesis -The Unitarianist Interface Hypothesis- according to which there is only one interface level called the Semantico-Phonetic Form at which both A-P and C-I performance systems can have access to a derivation comprising different types of features such as formal, phonological, and semantic features.

The major hypothesis of the research is that there is an iconic relationship between formal and phonological features. This hypothesis leads to two other hypotheses: 1) the acquisition of formal features has influence on the acquisition of intonation patterns for Iranian L2 learners of English; 2) the acquisition of formal features improves the phonetic performance of such participants.

\section{Theoretical Background}

Different lexical items have different types of features. These features are formal, phonological, and semantic. As different statements have different intonation patterns, Välimaa-Blum (2001) mentions that yes/no questions are

ExLing 2006: Proceedings of 1st Tutorial and Research Workshop on Experimental Linguistics, 28-30 August 2006, Athens, Greece 
incomplete in themselves without the answers, so they use the rising tone, but wh-questions have a falling tone.

With regards to the existence or non-existence of an iconic relationship between formal features and phonological features, Chomsky $(1995 ; 2000)$ assumes that the faculty of language consists of a cognitive system that stores information and some performance systems - A-P and C-I performance systems interacting with the cognitive system at two interface levels of $\mathrm{PF}$ and LF respectively-which are responsible for using and accessing information. Chomsky (1995) claims that a derivation converges finally if it converges at both PF and LF; otherwise, it crashes. With respect to the assumption that the convergence of a derivation is conditional upon its interpretability at both interface levels, he hypothesizes that there are no PF-LF interactions relevant to convergence.

Regarding what Chomsky (1995) believes in, Lotfi (2001) asserts that if there are no interactions between PF and LF, if the derivation D converges at PF but it crashes at LF, this means that D is to crash, at last. Now, how does PF 'find out' that D has crashed at LF that it will not be articulated phonetically? How do PF and LF communicate?

Based on the above question presented by Lotfi (ms.), he proposes the Unitarianist Interface Hypothesis, according to which there is only one interface level called the Semantico-Phonetic Form at which both performance systems can have access to a derivation.

\section{Design of the study Participants}

A group of forty Iranian L2 learners of English as a foreign language, both male and female age-ranged between twelve and sixteen were selected randomly from among Elementary level students of a private language school in Esfahan, Iran.

The participants were given both syntax and intonation pre-tests. Those participants who failed both tests were selected as the sample population of this study. This group was 24 participants who took part in the instruction.

\section{Materials}

Different types of materials were used during the study. There were syntax and intonation pre- and post-tests each of which was the parallel form of the other. In the syntax tests the participants were asked to identify grammaticality and ungrammaticality of the statements and also to make wh-questions. During the intonation tests the students had to read the statements and the questions aloud while their voice was being recorded. 
In addition to the above tests, two other types of materials were employed. The first one was a kind of booklet. It was researcher-made and composed of a reading passage and the grammatical point in question followed by a series of exercises. The grammatical point to be instructed to the participants was making wh-questions using the operation of movement. As it was supposed for the participants to actually see the movements, a number of cards on which different components of a statement or a question had been written were used, too. To move the cards more easily on the board a few magnets were also employed.

\section{Procedures}

During rating the tests various grammatical and phonological criteria were considered. For example, rating the syntax tests, deleting the element in question and substituting the wh-word were among the factors which had to be taken into account.

To rate participants' phonetic performance, a female native speaker's oral performance was employed as the criterion, so that participants' performance was compared using a computer software -Praat 4.1.1, (C) 19922003 by Paul Boersma and David Weenink.

In order to investigate the significance of the results of the study, the data obtained were subjected to the t-test in order to test the significance of the difference between the mean scores of the pre-tests and post-tests.

\section{Results}

To determine the participants' performance on syntax and intonation pretests, the mean procedure was employed. The mean score for the syntax pretest was 20.29 while the minimum and the maximum scores were 7 and 34 , respectively. The mean score for intonation pre-test was 14.8 while the minimum and maximum scores were 6 and 21. The mean scores of post-tests were also computed. The mean score of syntax post-test was 35.96 with minimum and maximum scores of 24 and 43; the mean score of intonation post-test was 22.80 with minimum and maximum scores of 16 and 27 .

To figure out whether the participants' performance on syntax and intonation pre- and post-tests were significantly different before and after the instruction the t-procedure was employed. The results indicated that $t$-test value for the syntax pre- and post-tests with the level of significance for twotailed test of .000 and df of 23 was 11.006 and that of the intonation posttests with the same level of significance and df was 7.582 


\section{Conclusion}

According to the results obtained from the data, it was indicated that there was an improvement in the grammatical and phonological performance of the participants before and after the instruction so that the mean scores of both post-tests were higher than those of the respective pre-tests. The results from the t-test procedures not only confirmed the usefulness of the instruction but also indicated the existence of an iconic relationship between formal and phonological features and the improvement in the acquisition of phonological features through the acquisition of formal ones.

Last but not the least, from a theoretical point of view, it can be said that the Unitarianist Interface Hypothesis was confirmed via this study; that is, different types of features in a lexical item are interpreted at the same interface level and that accordingly they have influence on each other. Moreover, empirically speaking, using movement operation as a technique to teach grammar proved to be useful in this study.

\section{Acknowledgements}

I would like to express my gratitude to Dr. A. R. Lotfi and Professor William Greaves for their helpful guidance during this research.

\section{References}

Chomsky, N. 1995. The minimalist program. Cambridge, MA, MIT Press.

Chomsky, N. 2000. Minimalist inquiries: The framework. In Martin, R., Michaels, D. \& Uriagereka, J. (eds.) 2000, Step by step: Essays on minimalist syntax in honor of Howard Lasnik, 89-155. Cambridge, MA, MIT Press.

Lotfi, A. R. 2001. Iconicity: A generative perspective. (Homepage) [Online] Available at URL: http://www.geocities.com.arlotfi/lotfipage.htm.

Lotfi, A. R. (ms.), Semantico-phonetic form: A unitarianist grammar. Peter Lang. [online], Available at URL: http://www.geocities.com/arlotfi/lotfipage.htm

Välimaa-Blum, R. 2001. Intonation and interrogation in English: Its all a matter of default. Semantique syntaxe et linguistique Anglaises. [Online], Available at URL: http://www.unice.fr/ANGLAIS/alaes/blum.htm. 